\title{
Design and Analysis of Modified SEPIC Converter with High Static Gain for Solar Photovoltaic System
}

\author{
Induja S.D ${ }^{1} \mid$ Dr.K.Yasoda ${ }^{2}$
}

${ }^{1}$ PG scholar, Department of EEE, Government College of Technology, Coimbatore, Tamilnadu, India,
${ }^{2}$ Assistant Professor, Department of EEE, Government College of Technology, Coimbatore, Tamilnadu, India,

To Cite this Article

Induja S.D and Dr.K.Yasoda, "Design and Analysis of Modified SEPIC Converter with High Static Gain for Solar Photovoltaic System”, International Journal for Modern Trends in Science and Technology, Vol. 06, Issue 07, July 2020, pp.:21-26; https://doi.org/10.46501/IJMTST060703

\section{Article Info}

Received on 22-May-2020, Revised on 22-June-2020, Accepted on 25-June-2020, Published on 27-June-2020.

\section{ABSTRACT}

Renewable power generation is the most importance in power sector. Renewable energy sources are more advantageous than fossil fuels because of their abundance and sustainability. Some examples are renewable energy sources as low power wind turbine, photovoltaic (PV) modules and other applications as fuel cells, embedded systems, portable electronic equipment's, uninterruptable power supply, and battery powered equipment. However application of renewable energy sources has some challenges because of their output characteristics. For instance the low output voltage of the PV panels must be boosted to be suitable for grid integration. Important researches are being done for the development of high static gain $D C-D C$ converters for several applications supplied by low dc output voltage power sources. Some of the requirements are necessary in this application such as reduced losses, high power density, low weight, and volume. An application where the proposed converters can be applied is the photovoltaic energy generation in grid-connected systems using the ac module or micro inverter structure. In usual, high-power grid-connected photovoltaic generation PV modules are connected in series in order to obtain the DC voltage level necessary for the inverter operation and energy can be transferred to the grid with low-current harmonic distortion. However, a common problem in this structure is the power losses due to the centralized maximum power point tracking (MPPT), mismatch losses among the PV modules, and generation reduction due to a partial shading of the series-connected PV modules

KEYWORDS: SEPIC converter, Static gain, Magnetic coupling.

Copyright (C) 2014-2020 International Journal for Modern Trends in Science and Technology

DOI: https://doi.org/10.46501/IJMTST060703

\section{INTRODUCTION}

Most of the domestic application focuses on the module-integrated converters where energy generated by the PV module is transferred to the grid through the high gain converter which can be integrated with the PV module system. Some of the main advantages of this PV generation structure are the modularity, allowing an easy increase of the installed power, the individual MPPT and reduction of the partial shading and panel mismatching effects, thus improving the energy-harvesting capability. However, Efficiency improvement, cost reduction, and the reliable operation throughout the module lifetime are some design challenges in 
ac module system. Commercial monocrystalline and multicrystalline PV module presents normally a maximum output power (PMPP) lowers than 350W with maximum power point voltage (VMPP) range from $15 \mathrm{~V}$ to $40 \mathrm{~V}$. In this condition, DC-DC converter input current and the converter conduction losses are maintained almost at the same level. The most part of the proposed solutions of non-isolated high static gain DC-DC converter are based on the boost topology with an additional technique associated. The main techniques used are the switch capacitors and voltage multiplier cells, switched inductors, inductor magnetic coupling and also combinations of these techniques as the integration of the voltage multiplier cell with the inductor magnetic coupling. The base topology presented in this paper is a modification of the SEPIC DC-DC converter and the main operation characteristics obtained with this modification comply with the requirements necessary in the high static gain applications. The basic structure without magnetic coupling presents a static gain close to twice of the classical boost converter and the switch voltage is close to half of the value obtained with the classical boost converter in the operation with high values of duty-cycle. The proposed solution using magnetic coupling is obtained including a secondary winding in an inductor of the converter, operating as a fly back transformer, increasing the static gain. The leakage inductance is a problem for the single switch isolated DC-DC converters resulting in switch overvoltage and the energy stored in the leakage inductance must be dissipated in snubber or clamping circuits. The energy stored in the leakage inductance is transferred to the converter output through the diodes and capacitor of the circuit. The voltages in all semiconductors are clamped by the intrinsic converter operation without dissipative components. The topology using magnetic coupling with the inclusion of an inductor auxiliary winding operating as a fly back transformer is also presented and studied in this paper in order to increase the static gain maintaining low switch voltage.

\section{OBJECTIVE}

$>$ To increase static gain.

$>$ To increase efficiency.

$>$ To maintain low switch voltage
III. BLOCK DIAGRAM

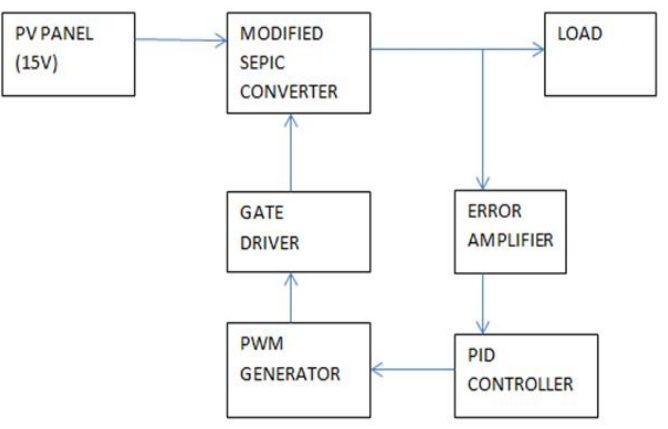

Fig.1 Block Diagram

\section{IV.DESCRIPTION}

The Modified SEPIC is essentially a boost converter followed by a buck-boost converter, therefore it is similar to a traditional buck-boost converter, but has advantages of having non-inverted output the output performance. It can be used for the high static gain application using renewable energy sources. The MPPT (maximum power point tracking) technique can be used to tap the high power output from the panel. The duty cycle are varied by the MPPT $(\mathrm{P} \& \mathrm{O})$ algorithm respectively to the error generated by the PID controller. Normally the duty cycle ratio is 0.8 for the switch.

\section{MODIFIED SEPIC CONVERTER WITHOUT MAGNETIC COUPLING}

The modification of the SEPIC converter is accomplished adding only two components with the inclusion of the diode DM and the capacitor $\mathrm{CM}$, as presented in Figure 2. Many operational characteristics of the classical SEPIC converter are changed with the proposed modification, as the elevation of the converter static gain. The capacitor $\mathrm{CM}$ is charged with the output voltage of the classical boost converter. The polarity of the CS capacitor voltage is inverted in the proposed converter and the expressions of the capacitors voltages and other operation characteristics are presented in the theoretical analysis.

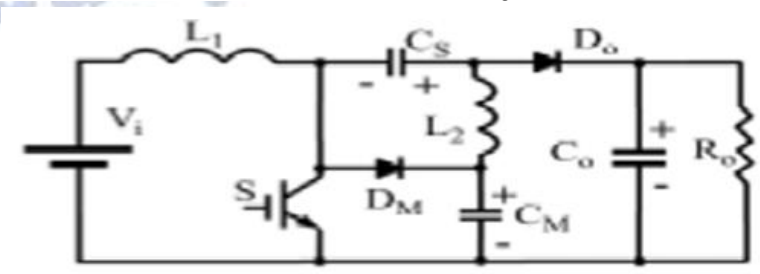

Fig.2 Modified SEPIC converter without magnetic coupling 


\section{1 Continuous conduction mode:}

At the instant $\mathrm{t} 0$, switch $\mathrm{S}$ is turned-off and the energy stored in the input inductor L1 is transferred to the output through the CS capacitor and output diode Do and also is transferred to the $\mathrm{CM}$ capacitor through the diode DM. Therefore, the switch voltage is equal to the CM capacitor voltage. The energy stored in the inductor L2 is transferred to the output through the diode Do.

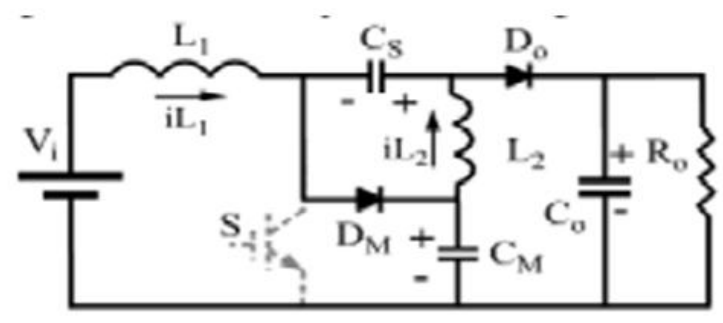

Fig.3 First operation stage without magnetic coupling

At the instant $\mathrm{t} 1$, switch $\mathrm{S}$ is turned-on and the diodes DM and Do are blocked and the inductors L1 and L2 store energy. The input voltage is applied to the input inductor L1 and the voltage VCS-VCM is applied to the inductor L2. The VCM voltage is higher than the VCS voltage.

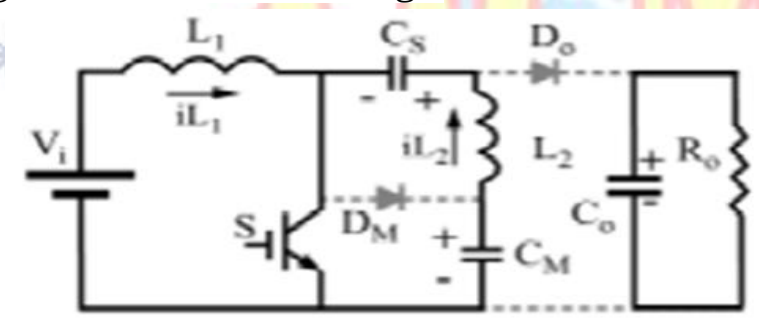

Fig.4 Second operation stage without magnetic coupling

The maximum voltage in all diodes and in the power switch is equal to the $\mathrm{CM}$ capacitor voltage. The output voltage is equal to the sum of the CS and CM capacitors voltage. The average L1 inductor current is equal to the input current and the average L2 inductor current is equal to the output current.

$$
\begin{aligned}
& \frac{\mathrm{V}_{0}}{\mathrm{~V}_{\mathrm{i}}}=\frac{1+\mathrm{D}}{1-\mathrm{D}} \\
& \frac{\mathrm{V}_{\mathrm{cm}}}{\mathrm{V}_{\mathrm{i}}}=\frac{1}{1-\mathrm{D}}
\end{aligned}
$$

The voltage across the CS capacitor is calculated by .

$$
\frac{\mathrm{v}_{\mathrm{cs}}}{\mathrm{V}_{\mathrm{i}}}=\frac{\mathrm{D}}{1-\mathrm{D}}
$$

The static gain of the proposed converter can be obtained considering null the average inductors voltage at the steady state and it is presented in
(5.1) considering the CCM operation.The CM capacitor voltage is calculated by (5.2) that is the same output voltage of the classical boost converter. The maximum switch voltage is equal to the VCM voltage. Therefore, the switch voltage will be lower than the converter output voltage.

\section{MODIFIED SEPIC CONVERTER WITH MAGNETIC COUPLING}

The modified SEPIC converter without magnetic coupling can operate with the double of the static gain of the classical boost converter for a high duty-cycle operation. A simple solution to elevate the static gain without increases the duty-cycle and the switch voltage is to include a secondary winding in the L2 inductor. The L2 inductor operation is similar to a buck-boost inductor and a secondary winding can increases the output voltage by the inductor windings turns ratio (n), operating as a fly back transformer. Figure 5 shows this alternate circuit.

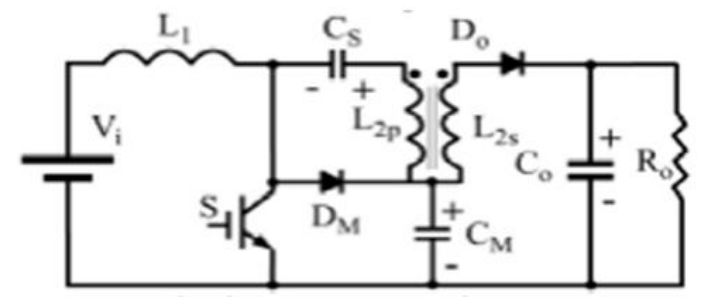

Fig.5 Modified SEPIC converter with magnetic
coupling

However, this converter structure presents the problem of overvoltage at the output diode Do due to the existence of the coupling winding L2 leakage inductance. The energy stored in the leakage inductance, due to the reverse recovery current of the output diode, results in voltage ring and high reverse voltage at the diode Do. This overvoltage is not easily controlled with classical snubbers or dissipative clamping. A simple solution for this problem is the inclusion of a voltage multiplier at the secondary side as presented in Figure. 6. This voltage multiplier increases the converter static gain, the voltage across the output diode is reduced to a value lower than the output voltage and the energy stored in the leakage inductance is transferred to the output. 


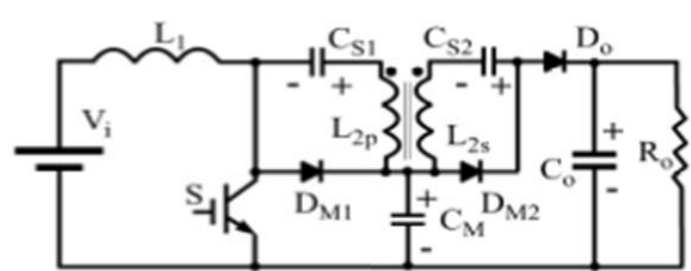

Fig.6 Modified SEPIC converter with magnetic coupling and output diode clamping

Therefore the secondary voltage multiplier composed by the diode DM2 and capacitor CS2 is also a non-dissipative clamping circuit for the output diode. The circuit presented in Figure 5.2 is the power circuit studied in this paper. The solutions based on the classical boost converter with magnetic coupling or the integration of the magnetic coupling and the voltage multiplier cell can present very high voltage gain and an excellent performance as presented. However, as the magnetic coupling is accomplished with the input inductor in the boost based solutions, the input current ripple is significantly increased and depends on the inductor winding turns ratio. Increasing the inductor turns ratio and the static gain, the input current ripple rises. The input current ripple increment is a non-desirables operation characteristic for some applications as the fuel cell power source. As the magnetic coupling is not accomplished with the input inductor in the proposed topology, the input current ripple is low and is not changed by the magnetic coupling.

\subsection{Continuous conduction mode:}

The continuous conduction mode operation of the modified SEPIC converter with magnetic coupling and output diode clamping presents five operation stages. All capacitors are considered as a voltage source and the semiconductors are considered ideals for the theoretical analysis.

1) First Stage [t0 - t1] (Fig. 7) - Condution happens through power switch $\mathrm{S}$ and the energy is stored by input inductor L1. The secondary winding L2S and diode DM2 charges the capacitor CS2. The leakage inductance limits the current and the energy transference happens in a resonant way. The output diode is blocked and the maximum diode voltage is equal to (Vo-VCM). At the instant $t 1$ the energy transference to the capacitor CS2 is completed and the diode DM2 is blocked.

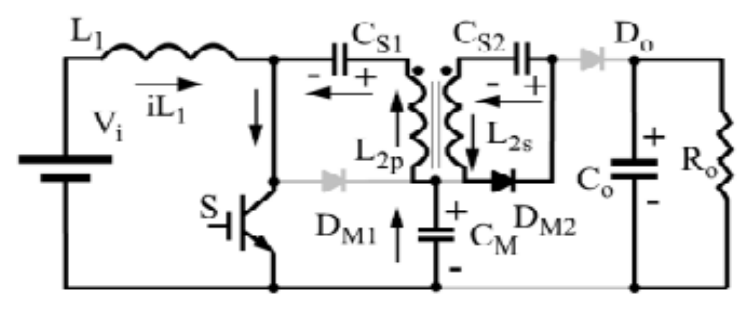

Fig.7 First operation stage with magnetic coupling

2) Second Stage [t1 - t2] ( Fig. 8) - From the instant $\mathrm{t} 1$, when the diode DM2 is blocked, the power switch is off to the instant $t 2$, energy is stored by the inductors L1 and L2 and there is linear increase in current.

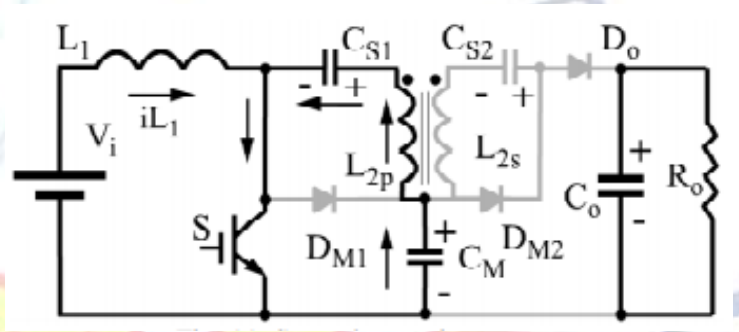

Fig. 8 Second operation stage with magnetic coupling

3) Third Stage [t2 - t3] (Fig. 9) - At the instant t2 the power switch $\mathrm{S}$ is turned off. Energy transfer happens from the inductor $\mathrm{L} 1$ to the capacitor $\mathrm{C} 1$. Also there is the energy transference to the output thought the capacitors CS1, CS2 inductor L2 and output diode Do.

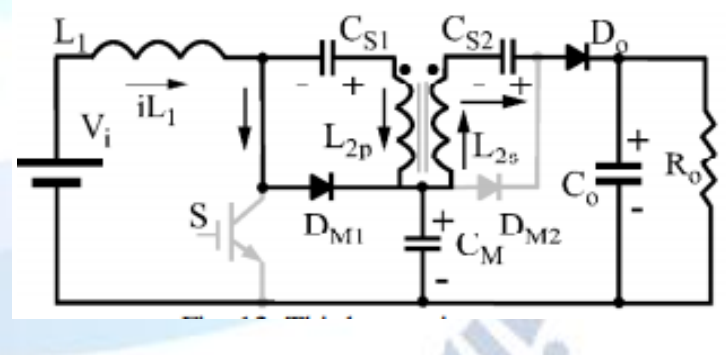

Fig.9 Third operation stage with magnetic coupling

4) Fourth Stage [t3 - t4] (Fig. 10) - At the instant $\mathrm{t} 3$, the energy transference to the capacitor $\mathrm{CM}$ is finished and the diode DM1 is blocked. The energy transference to the output is maintained until the instant $\mathrm{t} 4$, when the power switch is turned on. 


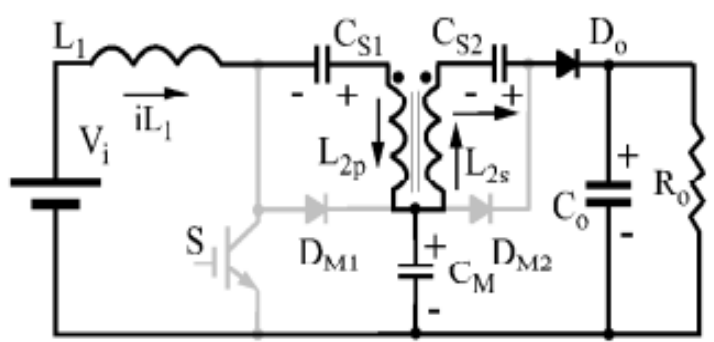

Fig.10 Fourth operation stage with magnetic coupling

5) Fifth Stage [t4 - t5] (Fig. 11) - When the power switch is turned on at the instant $t 4$, the current at the output diode Do linearly decreases and the $\mathrm{di} / \mathrm{dt}$ is limited by the transformer leakage inductance, reducing the diode reverse recovery current problems. When the output diode is blocked, the converter returns to the first operation stage.

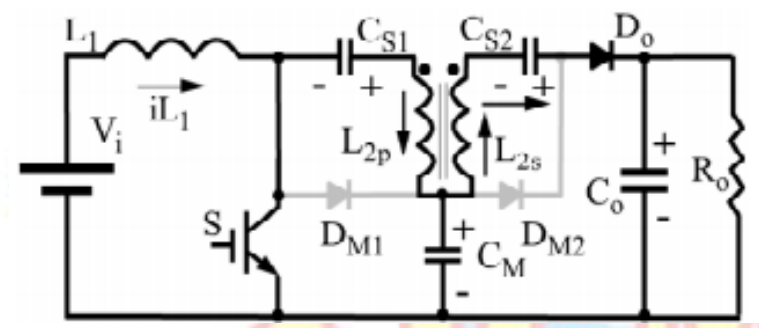

Fig.11 Fourth operation stage with magnetic coupling

The switch voltage and the voltage across all diodes are lower than the output voltage. The power switch turn on occurs with almost zero current reducing significantly the switching losses.

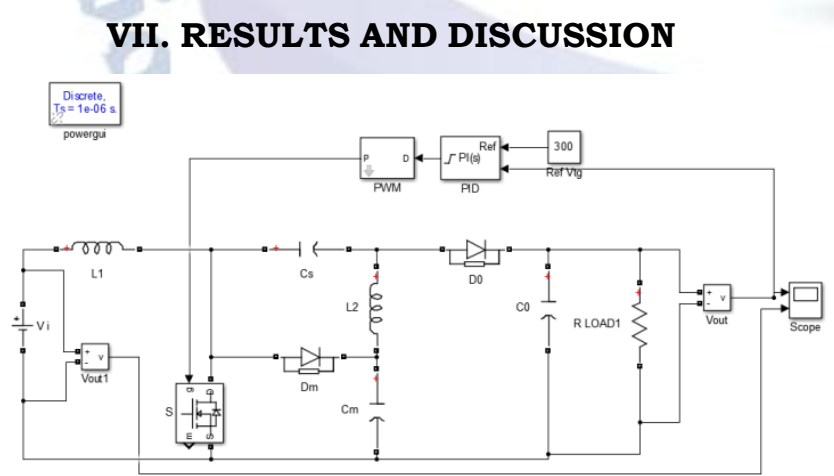

Fig.12 Matlabsimulink circuits for modified SEPIC converter without magnetic coupling

The figure 12 shows the implementation of modified SEPIC converter without magnetic coupling circuit diagram in MATLAB Simulink.
7.1 Simulation Waveform for without coupling

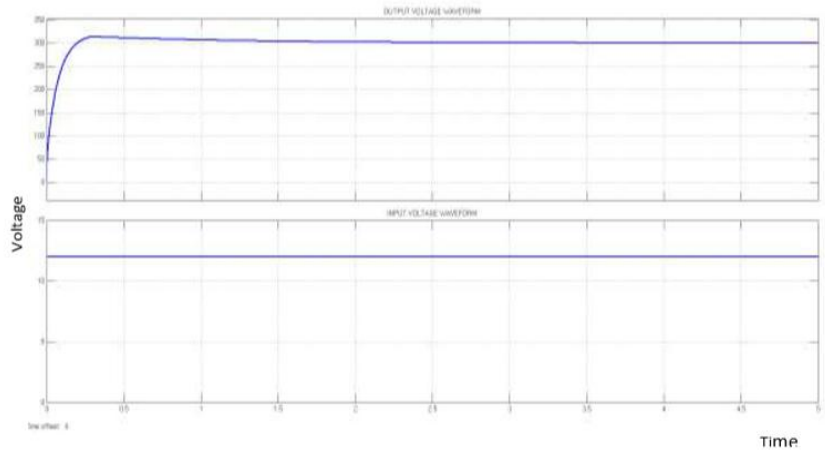

Fig.13 Output waveform for without magnetic coupling

$\mathrm{X}$-axis $=$ Time in sec

$\mathrm{Y}$-axis $=$ voltage $(\mathrm{V})$

Modified SEPIC converter shows increase of the input voltage up to 25 times. The details of the input and output voltage is given in the table 1 .

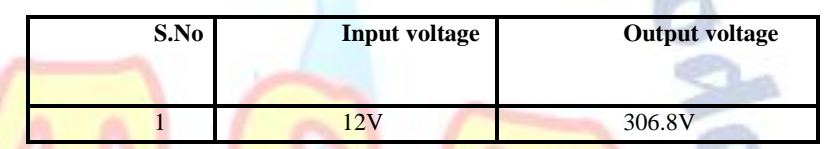

Table.1 Results for converter without magnetic coupling

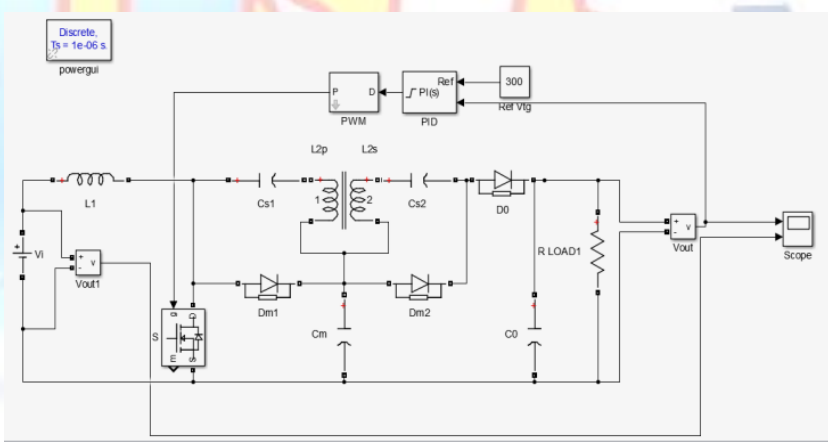

Fig.14 Matlabsimulink circuits for modified SEPIC converter with magnetic coupling

The figure 14 shows the implementation of modified SEPIC converter with magnetic coupling circuit diagram in MATLAB Simulink.

\subsection{Simulation Waveform for converter with coupling}

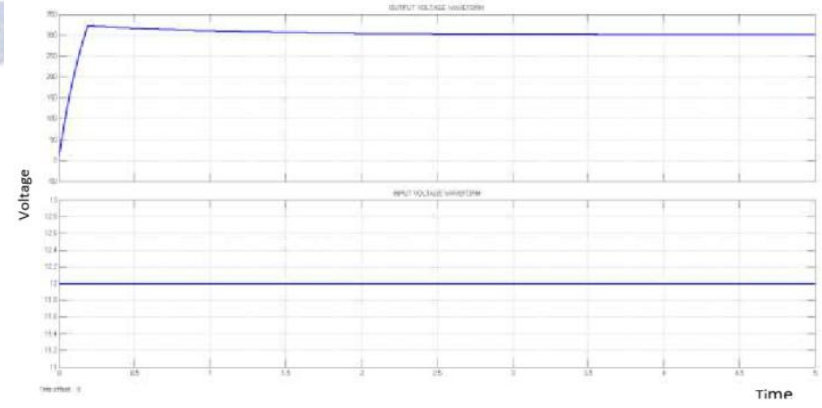

Fig.15 Output waveform for without magnetic coupling 
$\mathrm{X}$-axis $=$ Time in sec

$\mathrm{Y}$-axis $=$ voltage $(\mathrm{V})$

Modified SEPIC converter shows increase of the input voltage up to 25 times. The details of the input and output voltage is given in the table 2 .

\begin{tabular}{|c|c|c|}
\hline S.No & Input voltage & Output voltage \\
\hline 1 & $12 \mathrm{~V}$ & $309.8 \mathrm{~V}$ \\
\hline
\end{tabular}

Table.2 Results for converter with magnetic coupling

\section{CONCLUSION}

Two new topologies of non-isolated high static gain converters are presented in this paper. The first topology without magnetic coupling can operate with a static gain higher than 10 with a reduced switch voltage. The modified SEPIC converter without magnetic topology presents an efficiency of $91.9 \%$ at nominal power. The structure with magnetic coupling can operate with static gain higher than 20 maintaining low the switch voltage. The efficiency of proposed converter without magnetic coupling is equal to $92.2 \%$ operating with input voltage equal to $15 \mathrm{~V}$, output voltage around $300 \mathrm{~V}$ and output power equal 100 W.The diode reverse recovery current is reduced by the presence of transformer leakage inductance and the secondary voltage multiplier that operates as a non-dissipative clamping circuit to the output diode voltage. The presence of transformer leakage inductance reduces the turn-on commutation loss and reduced the negative effects of diode reverse recovery current. The efficiency obtained with both the topologies is adequate for many applications with high static gain.

\section{REFERENCES}

[1] Roger Gules, Walter Meneghette Dos Santos, Flavio Aparecido Dos Reis,Eduardo Felix Ribeiro Romaneli, And AlceuAndr"E Badin, Nov 2013 "A Modified Sepic Converter With High Static Gain For Renewable Applications," Ieee Trans. Power Electronics., Vol. 29, No. 11, Pp. 5860 5871.

[2] C. W. Li and X. He, Apr. 2011 "Review of non-isolated high step-up DC/DC converters in photovoltaic grid-connected applications," IEEE Trans. Ind. Electron., Vol. 58, No. 4, pp. 1239-1250.

[3] D. Zhou, A. Pietkiewicz, and S. Cuk, Jan 1999 "A Three-Switch high-voltage converter," IEEE Trans. Power Electron., Vol. 14, No. 1, pp. 177-183.

[4] D. Meneses, F. Blaabjerg, O. Garcia and J. A. Cobos, "Review and Comparison of Step-Up Transformerless Topologies for Photovoltaic AC-Module Application", IEEE Transactions on Power Electronics, vol. 28, no. 6, pp. 2649- 2663, June 2013.
[5] M. Prudente, L. L. Pfitscher, G. Emmendoerfer, E. F. Romaneli and R. Gules, "Voltage Multiplier Cells Applied to Non-Isolated DC-DC Converters", IEEE Transactions on Power Electronics, vol. 23, no 2, pp. 871-887, March 2008.

[6] E. H. Ismail, M. A. Al-Saffar, A. J. Sabzali and A. A. Fardoun, "A Family of Single-Switch PWM Converters With High Step-Up Conversion Ratio", IEEE Transactions on Circuits and Systems - I: Regular Papers, vol. 55, no. 4, pp. 1159-1171, May 2008

[7] B. Axelrod, Y. Berkovich and A. Ioinovici, "SwitchedCapacitor/Switched-Inductor Structures for Getting Transformerless Hybrid DC-DC PWM Converters", IEEE Transactions on Circuits and Systems I: Regular Papers, vol. 55, no. 2, pp. 687-696, March 2008.

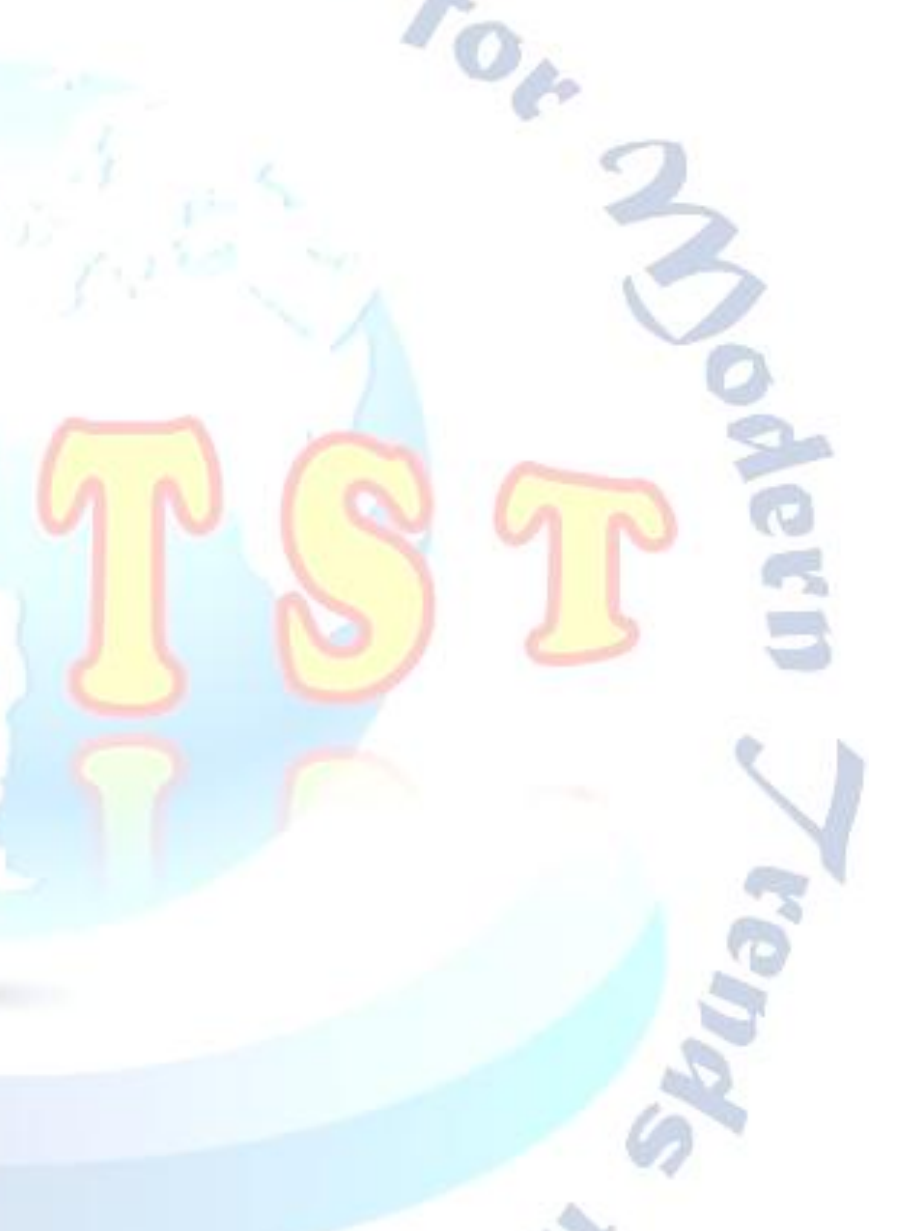

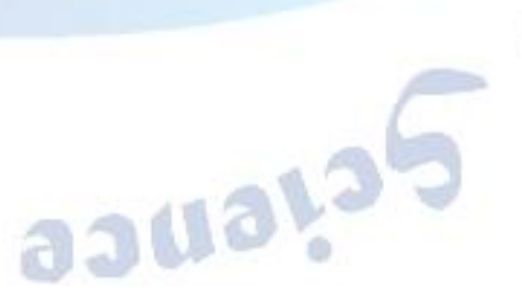

